\title{
In Vitro Study on the Influence of Proline on Struvite Crystals
}

\author{
Sevgi Polat (1D) Perviz Sayan (1D \\ Marmara University, Department of Chemical Engineering, Istanbul, Turkey
}

\section{ABSTRACT}

T his study investigated the effect of amino acid proline, as crystal modifier, on the struvite crystallization in vitro conditions. The struvite crystals were evaluated experimentally through XRD, SEM, and FTIR to determine the structure, morphology, and chemical composition, respectively. XRD analysis pointed out that struvite crystals belonged to the orthorhombic P $m n 2_{1}$ space group. SEM analysis depicted that proline had a significant influence on the morphology as well as the particle size of the struvite. Moreover, the length and width of struvite crystals varied with different concentrations of proline. The length of struvite crystals decreased, and their width thickened in the presence of the crystal modifier. The negativity of the zeta potential value became less negative in the presence of proline and the values were determined to be $-6.10 \mathrm{mV}$ and $-4.00 \mathrm{mV}$ for 25 and $100 \mathrm{ppm}$, respectively. According to BET analysis results, the surface area of the struvite decreased in the proline media when compared with the crystals formed without the crystal modifier. In addition, the thermal degradation of the formed crystals was examined. Regarding the results of the thermodynamic analysis, the average $\Delta H, \Delta G$, and $\Delta S$ were $92.17 \mathrm{~kJ} / \mathrm{mol}, 197.85 \mathrm{~kJ} / \mathrm{mol}$, and $-254.63 \mathrm{~J} / \mathrm{mol} \mathrm{K}$, respectively. As a result, this study could provide a potential crystal modifier for the inhibition of struvite stones.

\section{Keywords:}

Struvite, Crystal Morphology, Crystallization, Characterization, Proline.

\author{
Article History: \\ Received: 2020/05/03 \\ Accepted: $2020 / 11 / 28$ \\ Online: 2020/12/31
}

Correspondence to: Sevgi Polat, Marmara University, Deparment of Chemical Engineering, Istanbul, Turkey E-Mail:sevgi.polat@marmara.edu.tr

\section{INTRODUCTION}

Tn urolithiasis, stones are formed in the urethra, kidney, or bladder. Kidney stones cause severe pain in the abdomen and flank [1]. Supersaturation of urine leads to the formation of kidney stones, and their formation is dependent on the $\mathrm{pH}$, ionic strength, specific gravity, and solute concentration of urine [2]. Five types of urinary stones are primarily encountered: calcium oxalate, calcium phosphate, urates, cysteines, and magnesium ammonium phosphate hexahydrate $\left(\mathrm{MgNH}_{4} \mathrm{PO}_{4} \cdot 6 \mathrm{H}_{2} \mathrm{O}\right.$, struvite) [3,4]. Of these types of stone, struvite is unique owing to its association with the presence of infection in the urinary tract and thus struvite stones are also called infection stones $[1,4]$. The main cause of the infection is urease-producing organisms, such as Proteus spp., Klebsiella pneumoniae spp., and Providencia spp [5,6]. Urease is a characteristic bacterial enzyme that hydrolyzes the urea $\left(\mathrm{H}_{2} \mathrm{~N}-\mathrm{CO}-\mathrm{NH}_{2}\right)$ in urine to form ammonia $[1,5]$. As a result of this hydrolysis reaction, the $\mathrm{pH}$ of the urine and then the concentration of ammonia $\left(\mathrm{NH}_{4}^{+}\right)$and phosphate $\left(\mathrm{PO}_{4}{ }^{3-}\right)$ in the urine increases
[5]. These urea ions combine with the $\mathrm{Mg}^{2+}$ that is normally present in urine under alkaline conditions, leading to the formation of struvite [7,8]. Naturally formed struvite crystals usually exhibit coffin-like morphology, but when they grow rapidly dendrites can also occur [7,9]. The dendrite form of struvite crystals is particularly dangerous because they damage the epithelium of the urinary tract as they move through it [7]. If the problems related to struvite stones are not treated appropriately, kidney loss may be seen. Moreover, the high rate (up to 50\%) of recurrence of infection stones leads to serious medical problems [9]. Thus, the precipitation of struvite is an important medical research topic that needs to be addressed. Currently, urinary stones are usually treated using drug therapy for pain relief and inflammation reduction, whilst surgery is applied in extreme cases. Acetohydroxamic acid is prevalently used for treatment of patient suffering from struvite stones. However, the potential side effect of acetohydroxamic acid cannot be ignored. Thus, alternative ways to 
eliminate health problem related to struvite stones have gained a great importance [1]. For these reasons, many studies have been conducted on the struvite precipitation in urine to eliminate these problems with an alternative way. Li et al. proved the inhibitory effects of polyaspartic acid with different concentrations on the struvite crystallization [10]. Olszynski et al. revealed that nanosilver particles having different size and shape had a distinctive impact on the growth process of struvite in artifical urine in the presence of Proteus mirabilis [11]. They showed that nanosilver particles had an inhibitory effect on struvite formation depending on their size and shape and also observed that smaller particles exhibited greater negative effect on the growth of struvite. Moreover, Manzoor et al. performed a study to understand the role of vitamin $\mathrm{C}$ on struvite precipitation. They revealed that vitamin $\mathrm{C}$ or ascorbic acid modulated the formation of struvite crystals in the presence of uropathogenic bacteria [12]. The growth rate of the struvite crystals decreased depending on the increasing vitamin $\mathrm{C}$ concentration. Sayan et al. [13] researched the influence of different amino acids such as lysine, proline, alanine and tryptophane with different concentrations on struvite crystals at $37^{\circ} \mathrm{C}$ and $\mathrm{pH}$ 8. Adding these additives in studied concentrations did not lead to any changes in crystal morphology and structure. Although several studies are reported in the literature regarding struvite urinary stone formation, more research on struvite crystallization is still needed to find a viable method of removing struvite stones to give a suitable treatment alternative. Thus, studying the influence of crystal modifiers, especially biocompatible modifiers, on the precipitation of struvite is a highly attractive and promising research area to solve this problem. Proline, a type of nonessential amino acid, was studied in vitro as a crystal modifier to struvite crystallization media and found to be a potent inhibitor of struvite crystallization.

\section{MATERIAL AND METHODS}

Magnesium chloride hexahydrate $\left(\mathrm{MgCl}_{2} \cdot 6 \mathrm{H}_{2} \mathrm{O}\right)$, ammonium dihydrogen phosphate $\left(\mathrm{NH}_{4} \mathrm{H}_{2} \mathrm{PO}_{4}\right)$, L-proline $\left(\mathrm{C}_{5} \mathrm{H}_{9} \mathrm{NO}_{2}\right)$, and sodium hydroxide $(\mathrm{NaOH})$ were of reagent grade and purchased from Merck Company. Distilled water was utilized when preparing the solutions. All experiments were performed at least in triplicate.

The crystallization experiment was conducted in batch mode at $37^{\circ} \mathrm{C}$ in a double-jacketed crystallizer. $\mathrm{MgCl}_{2} \cdot 6 \mathrm{H}_{2} \mathrm{O}$ and $\mathrm{NH}_{4} \mathrm{H}_{2} \mathrm{PO}_{4}$ were used as the reactants for struvite crystallization. The procedure was as follow: Firstly, $1 \mathrm{M}$ $\mathrm{MgCl}_{2} \cdot 6 \mathrm{H}_{2} \mathrm{O}$ and $1 \mathrm{M} \mathrm{NH}_{4} \mathrm{H}_{2} \mathrm{PO}_{4}$ solutions were prepared. $300 \mathrm{ml}$ of $\mathrm{MgCl}_{2} \cdot 6 \mathrm{H}_{2} \mathrm{O}$ solution was put into the crystallizer. The solution was maintained at a constant temperature of $37 \pm 0.5^{\circ} \mathrm{C}$ using a thermostat. The stirring rate was 500 $\mathrm{rpm}$. When the solution reached its target temperature and equilibrium, the $\mathrm{NH}_{4} \mathrm{H}_{2} \mathrm{PO}_{4}$ solution was placed into the crystallizer via a peristaltic pump at a flow rate of $5 \mathrm{ml} / \mathrm{min}$. During the crystallization process, the $\mathrm{pH}$ of the solution was continuously followed and kept at $\mathrm{pH} 7.4$ using dilute sodium hydroxide.

The effect of proline and its concentration on the crystallization of struvite was examined in this study. Proline solution was added to the crystallizer via an infusion pump to provide the desired concentrations of 25 and 100 ppm in the crystallizer. At the end of the experiments, all suspension was taken from the crystallizer, filtered and collected the solid and liquid separately. Finally, the upper solid phase washed thoroughly with distilled water. The prepared crystals were dried at room temperature and the samples are kept for further analysis.

X-ray diffraction (XRD; Bruker D2 Phaser benchtop) was used to identify the phase structure of the struvite crystals. The functional groups of samples were confirmed by ATR method on a Fourier Transform-Infrared Spectrometer (FTIR; Shimadzu). The crystal size and morphology of the struvite were investigated by particle size analyzer (Malvern) and scanning electron microscopy (SEM, Zeiss EVO LS 10), respectively. The length and width of the struvite crystals were determined using Data Translation Image-Pro Plus image analysis software. BET analysis was performed by a Quantachrome Autosorb SI instrument to investigate the surface area of the products. Moreover, zeta potential of the samples was analyzed using a Malvern Zetasizer Nano ZS to detect the surface charge of the struvite. The thermal property of the struvite formed was determined using a Setaram LABSYS Evo thermogravimetric analyzer in a $\mathrm{N}_{2}$ atmosphere between $30{ }^{\circ} \mathrm{C}$ and $500{ }^{\circ} \mathrm{C}$ with a heating rate of $10^{\circ} \mathrm{C} / \mathrm{min}$.

\section{RESULTS AND DISCUSSION}

\section{XRD Analysis}

The structure analysis of the struvite crystals formed in the absence and presence of proline was performed and the XRD diffraction patterns are shown in Fig. 1. In pure media, the main diffraction peaks were distributed at $14.9^{\circ}, 20.8^{\circ}, 27.0^{\circ}$, and $33.2^{\circ}$, corresponding to crystal lattice planes (101), (111), (103), and (022) of struvite, indicative of high crystallinity of struvite. The relevant results were consistent with the literature reports $[14,15]$. The crystal obtained belonged to the orthorhombic Pmn $2_{1}$ space group. The diffraction peaks of the (101), (111), (103), and (022) crystal planes were observed among all the samples prepared under different conditions, which confirmed that the prepared crystals with and without proline were in the struvite form, indicating that no intermediate phase was occurred. 

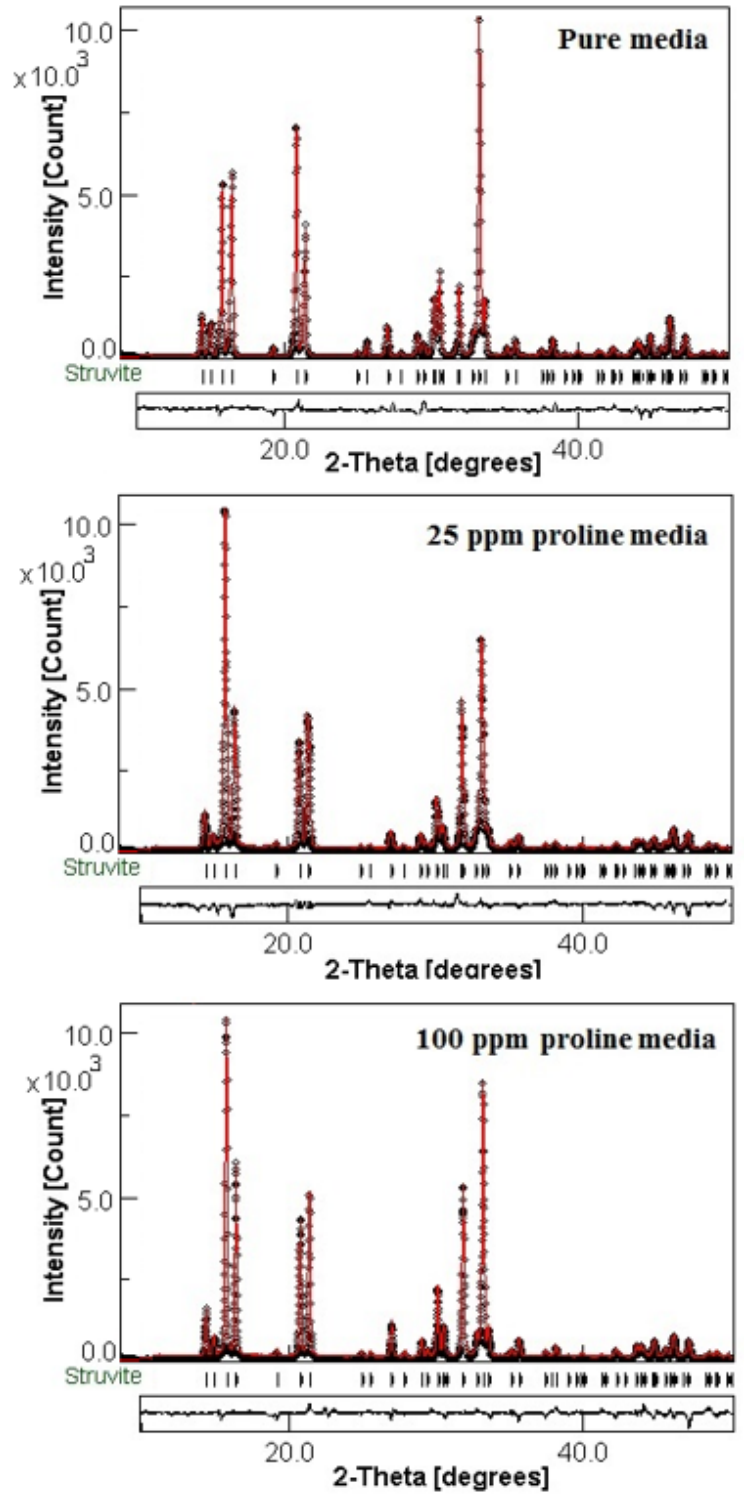

Figure 1. XRD results for struvite crystals obtained with and without proline

The addition of proline caused to change the intensity of the diffraction peaks. The $\mathrm{a}, \mathrm{b}$ and $\mathrm{c}$ unit cell parameters were $6.957 \AA$ А $6.138 \AA$, and $11.220 \AA$ for pure media, and these parameters were $6.970 \AA$ A , $6.147 \AA$, and $11.224 \AA$; $6.967 \AA$, $6.146 \AA$, and $11.225 \AA$ for the struvite crystals formed in the presence of 25 and 100 ppm media, respectively.

\section{FTIR Analysis}

The struvite samples prepared were characterized by FTIR spectrometer to identify the functional groups on the surface of the samples. FTIR was also used to analyze the adsorption of the proline modifier on the surface of struvite. Fig. 2 illustrates the spectra of struvite obtained in the absence and presence of proline. The FTIR result of the crystal obtained in pure media showed the specific peaks of struvite at $\sim 2900 \mathrm{~cm}^{-1}$ (N-H stretching), $\sim 2350$ $\mathrm{cm}^{-1}$ (O-H stretching), $1430 \mathrm{~cm}^{-1}$ (N-H stretching), and $\sim 980 \mathrm{~cm}^{-1}$ (PO43- stretching) which was consistent with the literature [16-18]. Furthermore, the peaks at $\sim 880$ $\mathrm{cm}^{-1}$ and $\sim 760 \mathrm{~cm}^{-1}$ were associated with the hydrogen bond in the absorption peaks of weak water-water and ammonium-water bonds, respectively.

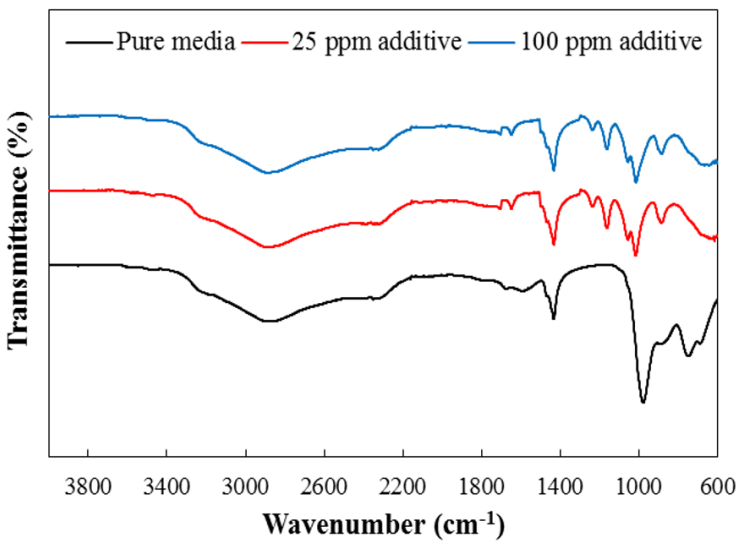

Figure 2. FTIR results for struvite crystals obtained with and without proline

Compared with the FTIR spectrum of struvite without crystal modifier, the new absorption bands between 1250 and $1100 \mathrm{~cm}^{-1}$ were observed for the struvite obtained with proline. Another important difference was the intensity of the peaks. These changes suggested that the proline interacted with the surface of the struvite.

\section{Zeta Potential Analysis}

To further reveal the adsorption characteristics of proline on struvite crystals, the surface charges of the crystals were measured, and the zeta potential analysis results are given in Fig. 3.

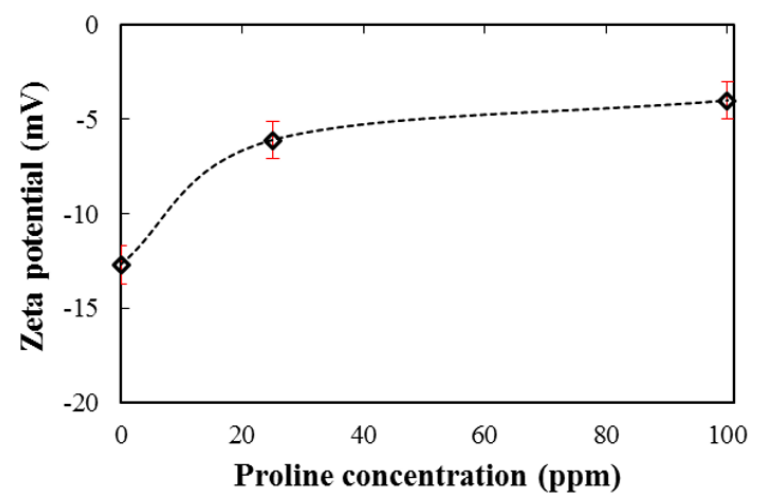

Figure 3. The variation of zeta potential with proline concentration 
The surface charge of the struvite crystals formed in pure media was $-12.70 \mathrm{mV}$. It can be seen in Fig. 3, the zeta potential value reached $-4.00 \mathrm{mV}$ at $100 \mathrm{ppm}$ crystal modifier concentration, compared with the value of $-6.10 \mathrm{mV}$ at $25 \mathrm{ppm}$ concentration. These results clearly illustrated that less negative surface charge value was obtained at higher proline concentration, which might result in more electrostatic repulsion between struvite surface and the positively charged proline species. Thus, crystal modifier concentra- tion increase can strengthen the proline adsorption, and finally increase in the inhibitory effect.

\section{Morphology Analysis}

To clarify the size and morphological changes of the crystals obtained under different proline concentrations, the SEM analysis were performed. The SEM images taken at different magnifications and the particle size distributions are shown in Fig. 4 and 5, respectively.
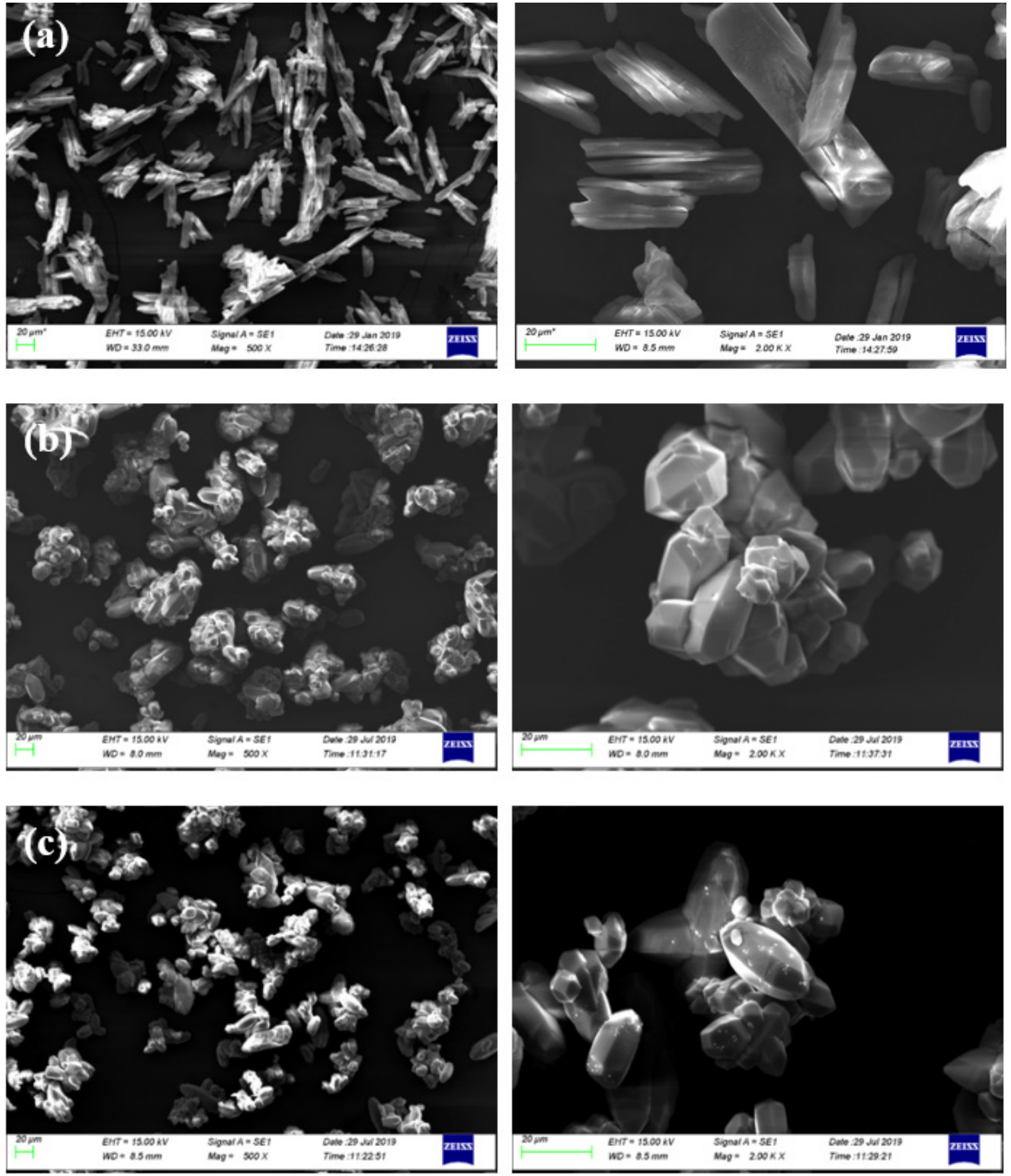

Figure 4. SEM photos of struvite crystals obtained in pure media (a), in the presence of $25 \mathrm{ppm}$ (b) and $100 \mathrm{ppm}$ (c) proline media 

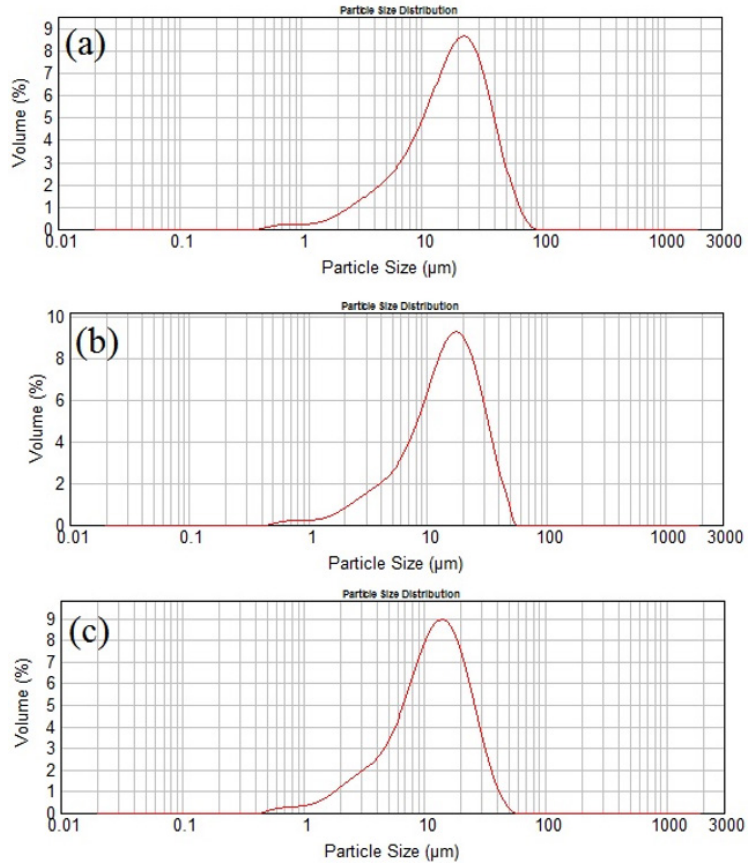

Figure 5. Particle size distributions of struvite obtained in pure media (a) and in the presence of $25 \mathrm{ppm}$ (b) and $100 \mathrm{ppm}$ (c) proline media

The rod-like struvite crystals with a mean size of 18.0 $\pm 1.8 \mu \mathrm{m}$ were synthesized in pure media. The struvite obtained in pure media had homogenous-looking and regular form. Meanwhile, they had the tendency of growing on each other and the surface of the rod-like crystals were porous.

The BET surface area of struvite obtained in pure media was determined to be $241.93 \mathrm{~m}^{2} / \mathrm{g}$. The length, width and aspect ratio of products are displayed in Fig. 6 . The length and width of struvite crystals varied with different concentrations of proline. The rod-like struvite crystals had an aspect ratio of $0.363 \pm 0.19$ and a mean length of $40.10 \pm$ $2.1 \mu \mathrm{m}$. According to SEM images, the crystal morphology of the struvite can be significantly changed with addition of the proline to crystallization media. Therefore, it is inferred that proline has ability to control the crystal morphology of struvite. The surface properties and morphology of struvite crystals were connected to the concentration of proline. By increasing the proline concentration to $25 \mathrm{ppm}$, the mean width reached to $20.0 \pm 2.9 \mu \mathrm{m}$ and the mean length dramatically decreased to $23.15 \pm 2.4 \mu \mathrm{m}$. The particle size of the samples obtained in the solutions with proline were reduced due to the surface adsorption of proline. As seen in Fig. 5, the mean particle size of the struvite crystals obtained in media supplemented with 25 and 100 ppm proline were 14.6 $\pm 2.2 \mu \mathrm{m}$ and $10.4 \pm 1.4 \mu \mathrm{m}$, respectively. The morphology results for the crystals obtained with varying concentrations of modifier are consistent with the particle size results.

At $100 \mathrm{ppm}$ proline concentration, the surface of the struvite crystals was smooth, non-porous and smaller

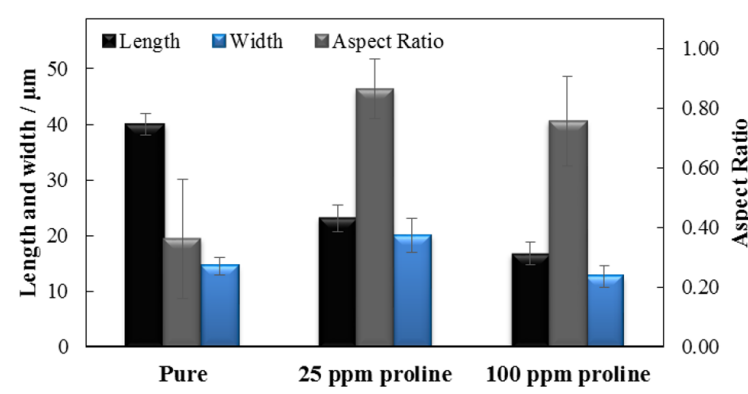

Figure 6. Effects of proline on the length, width, and aspect ratio of struvite crystals

crystals were precipitated. The BET surface area of the struvite crystals decreased $0.034 \mathrm{~m}^{2} / \mathrm{g}$ at $100 \mathrm{ppm}$, compared with the value of $9.30 \mathrm{~m}^{2} / \mathrm{g}$ at $25 \mathrm{ppm}$ modifier concentration. For specific surface area aspect, a higher proline concentration value led to a lower BET surface area. Fig. 6 shows that mean width and mean length of struvite crystals obtained with proline were determined to be $12.67 \pm 1.8 \mu \mathrm{m}$ and $16.75 \pm 1.9 \mu \mathrm{m}$, respectively. The quantitative variations in crystal morphology showed that with the increase of the proline concentration, the struvite crystals were shortened in length and enlarged in width, resulting in the increase of aspect ratio. The morphology results indicated that the presence of proline can effectively hindered the crystal nucleation and growth of struvite, and the magnitude of the effect depended on the proline concentration. Thus, it can be concluded that proline is an effective crystal modifier to control the crystal habit of struvite. The morphological transformation can be performed, short rod crystals with smaller particle size can be obtained in the presence of proline. This change could be explained by an adsorption mechanism. The adsorption of proline accounted for its interaction with struvite. Proline can bound on the active growth surface by chemical, physical forces and electrostatic interaction between proline and struvite; it could slow the growth rate on the crystal faces and thus lead to a modification of the habit of crystals grown in its presence of the crystal modifier.

\section{Thermal Analysis}

Thermogravimetric analysis was utilized for the evaluation of the thermal degradation behavior of struvite crystals obtained with and without crystal modifier. The TG and DTG curves are illustrated in Fig. 7. As observed in Fig. 7, the thermal degradation of struvite crystals obtained with and without proline included one main step, which corresponded to the ammonium degradation and the loss of water simultaneously in the temperature range of approximately $70-200{ }^{\circ} \mathrm{C}$ [19]. In accordance with the literature [20], the total weight loss of the struvite obtained without crystal modifier was $\sim 51.0 \%$. Unlike the crystals from the pure media, the increment of $1.8 \%$ was observed for the struvite obtained in media supplemented with 100 ppm proline. Moreover, the addition of 

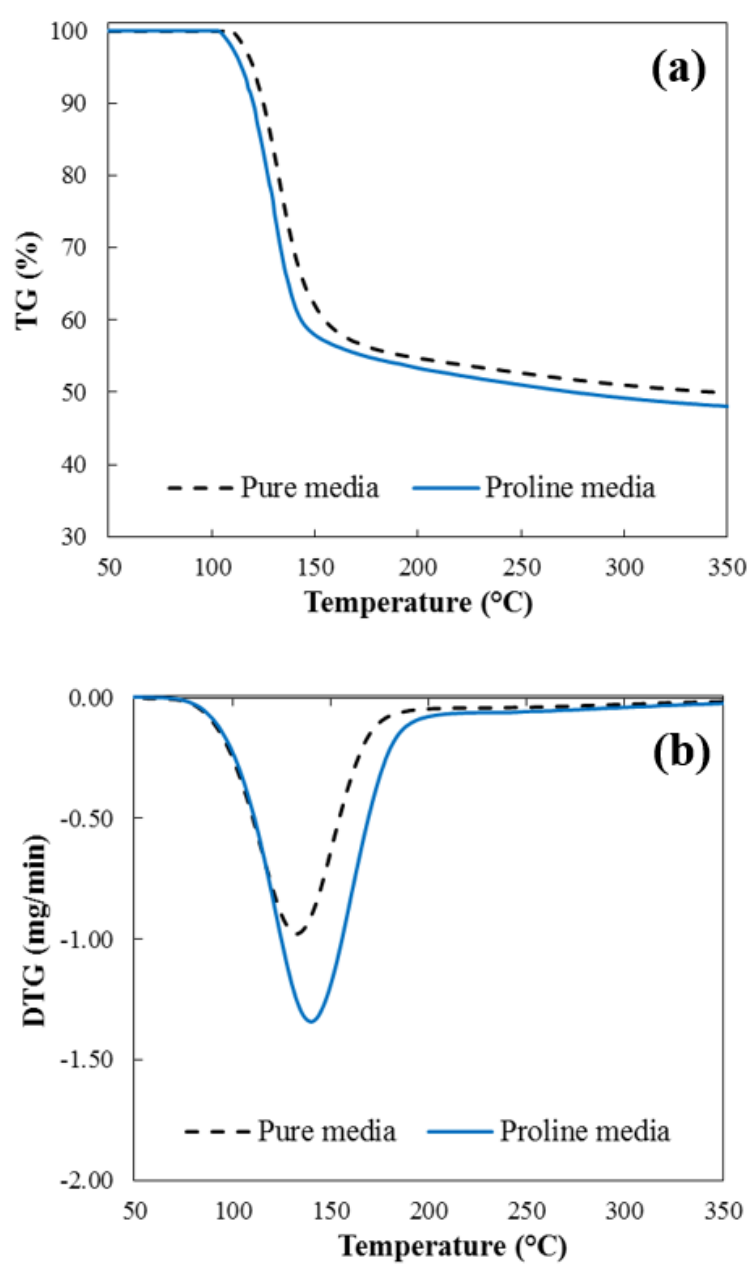

Figure 7. TG (a) and DTG (b) results of the struvite obtained with and without proline

the crystal modifier was found to shift the degradation temperature higher. The increased weight loss and shifting behavior of the peak temperature indicated that the proline adsorbed onto and interacted with the surface of the struvite.

In order to determine the activation energy during the thermal degradation of struvite, the Horowitz-Metzger equation was used for a first-order $(n=1)$ kinetic process as shown in Eq. (1) [21].

$$
\lg \left[\lg \left(\frac{w_{\alpha}}{w_{\gamma}}\right)\right]=\frac{E_{a} \theta}{2.303 R T_{\text {peak }}^{2}}-\lg 2.303
$$

Where $w_{\gamma}=w_{\alpha}-w, \theta=T-T_{\text {peak }}, E_{a}$ is the activation energy (kJ/mol), $T_{\text {peak }}$ is the peak temperature of DTG curve, $R$ is the ideal gas constant $(8.314 \mathrm{~J} / \mathrm{mol} \mathrm{K}), w_{\alpha}$ is the final sample weight, and $w$ is the sample weight at time $t$. According to the Eq. (1), when plotting of $\lg \left[\lg \left(w_{a} / w_{\gamma}\right)\right.$ versus $\theta$, the value of $\mathrm{E}_{\mathrm{a}} / 2.303 \mathrm{RT} \mathrm{T}_{\text {peak }}{ }^{2}$ is obtained from the slope of the graph and the activation energy is calculated by using this relation. Moreover, the thermodynamic parameters such as the enthalpy $(\Delta \mathrm{H})$, entropy $(\Delta \mathrm{S})$, and Gibbs free energy $(\Delta \mathrm{G})$ were also calculated.

The thermodynamic parameters such as enthalpy change $(\Delta H)$, Gibbs free energy change $(\Delta G)$, and entropy change $(\Delta S)$, were calculated using Eyring equations [22].

$$
\begin{aligned}
& \Delta H=E_{\alpha}-R T \\
& \Delta G=E_{\alpha}+R T_{\text {peak }} \ln \left(\frac{K_{B} T_{\text {peak }}}{h A}\right) \\
& \Delta S=\frac{\Delta H-T \Delta G}{T_{\text {peak }}}
\end{aligned}
$$

Where $K_{B}$ is the Boltzmann constant, and $\mathrm{h}$ is the Planck constant.

The activation energy was $95.6 \mathrm{~kJ} / \mathrm{mol}$ for the struvite crystals obtained without crystal modifier. The values of $\Delta \mathrm{H}, \Delta \mathrm{G}$ and $\Delta \mathrm{S}$ were determined to be $92.17 \mathrm{~kJ} / \mathrm{mol}, 197.85$ $\mathrm{kJ} / \mathrm{mol}$, and $-254.63 \mathrm{~J} / \mathrm{mol} . \mathrm{K}$, respectively. The positive value of $\Delta \mathrm{H}$ calculated for the crystals attributed to the endothermic nature of thermal degradation process. The negative $\Delta S$ entropy value revealed the decrease in randomness during the degradation process. The positive $\Delta \mathrm{G}$ showed that the degradation process of the struvite was nonspontaneous.

\section{CONCLUSION}

In this study, the proline used as the crystal modifier with different concentration was studied to modify the crystal size and morphology of the struvite. XRD results showed that the crystals obtained were in orthorhombic structure. SEM images showed that proline had a significant modification effect on struvite morphology. With the increase of the proline concentration, the struvite crystals were shortened in length and enlarged in width, resulting in the increase of aspect ratio. In the presence of $100 \mathrm{ppm}$ proline, the aspect ratio of struvite was $0.756 \pm 0.15 \mu \mathrm{m}$ with the mean length of $16.75 \pm 1.9 \mu \mathrm{m}$. Zeta potential measurements showed that proline played a significant role in controlling the crystal surface charge during the crystal growth process. The value of zeta potential decreased along with the increase of crystal modifier concentration. The surface of the crystals became less negative in the presence of proline. From the characterization results, it is possible to conclude that proline has the ability to change the crystal size and morphology and it can be used a potential crystal modifier for the inhibition of struvite stones. In addition to characterization analysis, thermal degradation of the struvite crystals was investigated in this study. According to the kinetic analysis performed by Horowitz-Metzger model, the calculated activation energy value was $95.6 \mathrm{~kJ} / \mathrm{mol}$. 


\section{References}

1. Das P. Gupta G, Velu V, Awasthi R, Dua K. Formation of struvite urinary stones and approaches towards the inhibition-A review. Biomed. Pharmacother. 96 (2017) 361370.

2. Manzoor MAP, Mujeeburahiman M, Ram Duwal S, Rekha P.D. Investigation on growth and morphology of in vitro generated struvite crystals. Biocatal. Agric. Biotechnol. 17 (2019) 566-570.

3. Griffith DP. Struvite stones. Kidney International. 13 (1978) 372-382.

4. Clapham L, Mclean RJC, Nickel JC, Downey J, Costerton, JW. The influence of bacteria on struvite crystal habit and its importance in urinary stone formation. J. Cryst. Growth. 104 (1990) 475-484.

5. Prwyer J, Olszynski M. Influence of disodium EDTA on the nucleation and growth of struvite and carbonate apatite. J. Cryst. Growth. 375 (2013) 108-114.

6. Siener R, Struwe $F$, Hesse A. Effect of L-methionine on the risk of phosphate formation. Urology. 98 (2016) 39-43.

7. Olszynski M, Prywer J, Mielniczek-Brzoska E. Inhibition of struvite crystallization by tetrasodium pyrophosphate in artificial urine: Chemical and physical aspects of nucleation and growth. Cryst. Growth Des. 16 (2016) 3519-3529.

8. Olszynski M, Prwyer J, Torzewska A. Effects of size and shape of nanosilver particles on struvite and carbonate apatite precipitation. Cryst. Growth Des. 15 (2015) 33073320.

9. Abbona F, Boistelle R. Growth morphology and crystal habit of struvite crystal $\left(\mathrm{MgNH}_{4} \mathrm{PO}_{4} \cdot 6 \mathrm{H}_{2} \mathrm{O}\right)$. J. Cryst. Growth. 46 (1979) 339-354.

10. Li H, Yao QZ, Wang YY, Li YL, Zhou GT. Biomimetic synthesis of struvite with biogenic morphology and implication for pathological biomineralization. Sci. Rep. 5 (2018) 7718.

11. Olszynski M, Prywer J, Torzewska A. Effect of size and shape of nanosilver particles on struvite and carbonate apatite precipitation. Cryst. Growth Des. 15 (2015) 3307-3320.
12. Manzoor MAP, Duwal SR, Mujeeburahiman M, Rekha PD. Vitamin $C$ inhibits crystallization of struvite from artificial urine in the presence of Pseudomanas aeruginosa. Int. Braz. J. Urol. 44 (2018) 1234-1242.

13. Titiz-Sargut S, Sayan P, Masum A, Kiran B. Effect of Amino Acids on Magnesium Ammonium Phosphate Hexahydrate (Struvite) Crystallization. Iranian Journal of Chemical Engineering. 11 (2014) 3-18.

14. Kumari S, Jose S, Tyagi M, Jagadevan S. A holistic and sustainable approach for recovery of phosphorus via struvite crystallization from synthetic distillery wastewater. J. Clean. Prod. 254 (2020) 120037.

15. Prywer J, Torzewska A. Biomineralization of struvite crystals by Proteus mirabilis from artificial urine and their mesoscopic structure. Cryst. Res. Technol. 45 (2012) 12831289.

16. Chauhan CK, Joshi MJ. In vitro crystallization, characterization and growth-inhibition study of urinary type struvite crystals. J. Cryst. Growth. 362 (2013) 330337.

17. Bindhu B, Thambi TA. Formation and Microanalysis of Struvite Urinary Calculi. International Journal of Engineering Research and Applications. 2 (2012) 1480-1485.

18. Polat S, Sayan P. Application of response surface methodology with a Box-Behnken design for struvite precipitation. Adv. Powder Technol. 30 (2019) 2396-2407.

19. Tansel B, Lunn G, Monje O. Review: struvite formation and decomposition characteristics for ammonia and phosphorus recovery: a review of magnesium-ammonia phosphate interactions. Chemosphere. 194 (2018) 504-514.

20. Frost RL, Weier ML, Erickson KL. Thermal Decomposition of Struvite- Implications for the decomposition of kidney stones. J. Therm. Anal. Calorim. 76 (2004) 1025-1033.

21. Horowitz HH, Metzger G. A new analysis of thermogravimetric traces. Anal. Chem. 35 (1963) 1464-1468.

22. Fernandez A, Mazza G, Rodriguez, R. Thermal decomposition under oxidative atmosphere of lignocellulosic wastes: different kinetic model application. J. Environ. Chem. Eng. 6 (2018) 404-415. 